\title{
Generalized Muscle Weakness
}

National Cancer Institute

\section{Source}

National Cancer Institute. Generalized Muscle Weakness. NCI Thesaurus. Code C78323.

A reduction in the strength of muscles in multiple anatomic sites. 